\section{Apoio social esaúde: contribuições das ciências sociais e humanas às intervenções em saúde}

Social support and health: contributions of the social and human sciences to health interventions

\section{Tonantzin Ribeiro Gonçalves ${ }^{2}$}

As evidências sobre o impacto das relações sociais sobre a saúde física e mental das pessoas tem se acumulado e sua influência sobre os riscos de mortalidadejá tem sido comparada a outros fatores bem estabelecidos como o fumo, a obesidade e o sedentarismo ${ }^{1}$. Porém, a associação entre relações sociais e saúde éum tema complexo e permanece um desafio derivar model os teóricos e intervenções que contemplem as múltiplas inter-relações entre ambos os aspectos. Particularmente, as dificuldades se agravam porque a influência de variáveis que remetem a um construto social tem ação indireta sobre o fenômeno (por exemplo, a relação entre apoio social e saúde), diferenciandose, portanto, de fatores de risco clássicos com relação causal direta (como fumar eter câncer de pulmão) quepossibilitam isolar o poder preditivo das variáveis. Cada vez mais é necessário adotar uma perspectiva multinível na análise dos determinantes sociais da saúde, onde se inclui as relações sociais, o que exige um maior refinamento teórico e metodológico. Assim, é essencial aprofundar o debate conceitual sobre como as relações sociais podem afetar a saúde e, neste sentido, 0 artigo de Canesqui e Barsaglini é oportuno ao buscar ma- pear as contribuições das ciências sociais e humanas. M esmo que as autoras representem tendências da literatura apenas até 2005 , a revisão sublinha carências e necessidades ainda atuais no que tange a articulação entre apoio social e saúde. Uma rápida busca na base de dados M edline com o termo apoio social resulta em mais de 50.000 citações, endossando o desafio tomado pelas autoras em abarcar tão vasta literatura.

Até o leitor mais casual deve notar, desde já, a intenção de enfatizar o papel das relações sociais ao invés do uso do termo apoio social, que me parece mais apropriado para designar a discussão proposta por Canesqui e Barsaglini. Assim, considero oportuno delimitar duas das principais tendências conceituais que tem perpassado os estudos e os discursos na área a fim de melhor contextualizar alguns dos achados das autoras e ampliar a discussão sobre as implicações destas para as intervenções em saúde, em especial no âmbito da saúde pública.

No primeiro plano, o termo apoio social tem sido utilizado, de modo geral, para descrever o processo por meio do qual as relações sociais podem promover saúde e bem-estar, a partir da provisão ou troca emocional, informativa e instrumental em resposta à percepção de que ou tros precisam de ajuda. Tal suporte acontece, muitas vezes, em situações pontuaisou crônicas de estresse como doenças, transições desenvolvimentais e eventos vitais. A noção de rede de apoio se articula aí na medida em que caracteriza a estrutura dos vínculos sociais, enquanto o apoio social seria a dimensão funcional ou qualitativa dessa rede que se traduz nosrecursos percebidos como disponíveis pela pessoa nas suas relações formais ou informais para atender a necessidades específicas. Essa tradição tem inspirado grande parte da produção empírica na área, sendo os modelos cognitivo e da teoria do estresse, e das relações interpessoais os mais popularmente utilizados, como destacado pelas autoras. Predomina o uso de métodos quantitativos focados na avaliação da percepção individual sobre o apoio recebido e, menos frequentemente, sobre o apoio ofertado, cujas evidências têm baseado uma grande variedade de intervenções que buscam diminuir o impacto de situações estressantes sobre a saúde dos indivíduos por meio da promoção de apoio formal ou informal ${ }^{2}$. Contudo, ao tentar isolar efeitos do apoio percebido so-

${ }^{1}$ Programa de Pós-Graduação em Psicologia, Universidade Federal do Rio Grande do Sul. tonanrib@yahoo.com.br 
bre a saúde, tais proposições sofrem críticas no que se refere à ambiguidade, muitas vezes inevitável, das medidas, que podem incluir tanto aspectos da personalidade quanto dos processos sociais ao mesmo tempo. Além disso, parece haver o privilégio aos efeitos do apoio no indivíduo e, consequentemente, as intervenções tendem a enfocar grupos de pessoas sob maior risco psicossocial (p.ex., pessoas vivendo com doenças crônicas), atingindo apenas o nível micro contextual.

Por outro lado, concordando com as autoras e outros pesquisadores, defende-se que para além da noção de apoio enquanto recurso, outros processos sociais podem influenciar a saúdee, inclusive a possibilidade de obter e prestar apoio aos outros $^{3-4}$. D esse modo, outra tendência tem se centrado nos benefícios e riscos à saúde que resultam não apenas da conformação de redes e do apoio social, mas de aspectos como a coesão, a confiança, a re ciprocidade, o senso de pertença e a participação social. N essa posição, as relações sociais podem regular emoções, cognições, comportamentos, crenças e até respostas biológicas mediante interações e condicionamentos que não são necessariamente voltados para a troca de apoio, mas atuam na promoção de saúde e/ou produção de vulnerabilidades. A saúde é vista como produto da vida social, ou seja, de como as pessoas vivem e organizam suas vidas frente as suas condições sociais, tornando central a sua dimensão relacional, sóciohistórica e política. N essa direção, a teoria social contemporânea tem contribuído para ampliar o escopo das intervenções em saúde, sendo um dos conceitos expoentes o decapital social, contemplado por Canesqui e Basaglini. Todavia, a associação entre capital social e saúde enfrenta críticas devido à dificuldade de operacionalizar emedir o construto, particularmente no que se refere a análises macro-contextuais (i.e., cidade, estado, nação), deabarcar aspectos negativos ligados ao corporativismo, às relações de poder e políticas e pela existência de conceitossimilarese consagradosnaliteratura (i.e., senso de comunidade, empoderamento, coesão social) $)^{5}$. Quanto à aplicação de tais conceitos no contexto brasileiro, esta é ainda muito escassa e exige refino teórico, pois não haveria uma forte tradição associativa no país que facilitasse a produção de capital social público, além de achados apontarem a desconfiança como uma característica marcante de nossa sociedade, contrapondo-se a uma dimensão central do construto.

Estebreve percorrido procurou recolocar esintetizar as diversas correntes teóricas discutidas pelas autoras. Foi visto que enquanto 0 apoio social liga-se principalmenteao nível individual egrupal, conceitos como o capital social e a coesão social pretendem abranger o nível comunitário mais amplo das relações sociais e que essas diferentes concepções tem implicações específicas para o modo como são pensadas as intervenções em saúde. Em última instância, o debate em torno das distintas posições teóricas sobre a associação entre relações sociais e saúde reflete também o esforço por modificar as bases conceituais da saúde pública, onde a busca por transformação social e pela integralidade da atenção à saúde exige uma visão sistêmica dos determinantes sociais da saúde, a mobilização de atores locais e a construção de redes intersetoriais de cooperação. Entretanto, apesar da compreensão crescente de que novas formas de intervenções em saúde precisam incluir valores de empoderamento e participação comunitária, tais valores são frequentemente justapostos a prescrições padronizadas de práticas comportamentais e corporais que visam a reduzir a prevalência defatores derisco individuais ${ }^{6}$, conduta que parece se aliar ao estudo das influências das relações sociais sobre a saúde por meio do conceito de apoio social. Desse modo, parece haver um conflito entre a base científica em saúde pública e as práticas inovadoras que estão emergindo na área e que se baseiam em parcerias intersetoriais entre instituições sociais e sociedade civil. Por isso, alguns pesquisadores defendem que precisamos reconsiderar tanto a natureza das práticas em saúde pública quando a sua posição epistemológica na implementação e na avaliação de políticas ${ }^{6}$.

Questiona-se, portanto, a tradução acrítica de evidências produzidas por abordagens positivistas de ciência nas políticas públicas em saúde, sem que se faça uma interpretação contextualizada e consensual que conjugue os pontos de vista de todos os atores relevantes e possibilite uma melhor aplicação local das recomendações. Por esse motivo, o uso de métodos qualitativos rigorosos na aval iação e pesquisa em saúde pública seria muito útil, o mesmo aplicando-se para as investigações em relações sociais e saúde. Devemos então abandonar o conceito de apoio social em prol deoutros como os de coesão e capital social? A resposta seria: sim e não. Sim, porque, em termos paradigmáticos, precisamos de bases teóricas mais apropriadas às intervenções em saúde pública pelos motivos acima expostos e que não são contemplados por uma tradição que enfoca apenas o indivíduo e seus grupos imediatos na busca por identificar fatores de risco e proteção populacionais. Não, porque, enquanto estratégia de construção de conhecimento científico, a operacionalização do conceito de apoio social e o uso de métodos quantita- 
tivos no estudo das associações entre relações sociais e saúde podem contribuir (mesmo com as limitações que qualquer teoria e método em ciência carrega) ao fornecer quadros gerais sobre essas associações em nível microcontextual que devem ser complementados por explorações qualitativas e por análises queenvolvam múltiplosníveis. Ademais, vale lembrar que permanece fundamental abordar os indivíduos e as desigualdades em saúde que suas redes sociais atualizam, estendendo abordagens que atacam as necessidades de saúde no nível populacional?.

Em suma, o debate procurou contextualizar e problematizar al gumas das contribuições do artigo Apoio social e saúde: ponto de vista das ciências sociais ehumanas para a pesquisa eintervenção em saúde. 0 apoio social tem sido utilizado como uma rubrica geral que abarca conceitos muito distintos como aqueles que se referem ao apoio percebido/ ofertado eaqueles relativos ao capital social, sendo necessária maior precisão teórica ao utilizá-los. Diferentes medidas envolvem a avaliação desses conceitos e não é de surpreender que, por vezes, demonstrem resultados divergentes entresi equanto ao seu impacto em desfechos de saúde ${ }^{8}$. Ainda, abordagens quantitativas sobre a associação entre relações sociais e saúde são criticadas por desconsiderarem a importância do contexto, da cultura e da diversidade das práticas sociais, enquanto abordagens qualitativas encontram resistências para fazer valer, na prática, o conhecimento que produzem. Apesar da diversidade de posições em torno do tema, concorda-se que mesmo que todos experienciem eventos estressantes ao longo da vida os ef eitos destes so bre a saúde são maiores para aqueles indivíduos e grupos sociais que tem menor apoio social, redes sociais pobres, uma habilidade limitada para controlar seu ambiente/situação social ebaixos níveis deintegração e participação social. Por isso, intervenções em saúde devem contemplar tanto estratégias voltadas para as redes de apoio em maior vulnerabilidade social, visando diminuir as desigualdades, mas também estratégias que promovam relações sociais mais participativas que irão impactar indicadores populacionais de saúde.

\section{Referências}

1. Holt-Lunstad J, Smith TB, Layton JB. Social Relationships and Mortality Risk: A M eta-analytic Review. PLOS M ed [serial on the Internet] 2010 [cited 2012 Mar 29];7(7):[about 20 p.]. Available from: http:// dx.doi.org/10.1371\%2Fjournal.pmed. 1000316
2. Gonçalves TR, Pawlowski J, Bandeira DR, Piccinini CA. Avaliação de apoio social em estudos brasileiros: aspectos conceituais e instrumentos. Cien Saude Colet 2011; 16(3):1755-1769.

3. Cohen S, Gottlieb BH, Gordon LU. Social relationships and health. In: Cohen S, Gordon LU, Gottlieb $B H$, editors. Social support measurement and intervention: a guide for health and social scientists. $\mathrm{New}$ York, Oxford: Oxford University Press; 2000. p. 3-25.

4. Souza EM. Intergenerational integration, social capital and health: a theoretical framework and results from a qualitative study. Cien Saude Colet 2011; 16(3): 1733-1744.

5. Pattussi MP, M oysés SJ, Junges JR, Sheiham A. Capital social e a agenda de pesquisa em epidemiologia. Cad Saude Publica 2006; 22(8):1525-1546.

6. Potvin L, Gendron S, Bilodeau A, Chabot P. Integrating social theory into public health practice. Am J Public Health 2005; 95(4):591-595.

7. Frohlich $\mathrm{KL}$, Potvin L. Transcending the known in public health practice: the inequality paradox: the population approach and vulnerable populations. Am J Public Health 2008; 98(2):216-221.

8. Barerra M. Distinctions between social support concepts, measures, and models. Am J Community Psychol 1986;14(4):413-445. 